\section{Inside and Out: Factors That Support and Hinder the Self-Advocacy of Undergraduates with ADHD and/or Specific Learning Disabilities in STEM}

\author{
Mariel A. Pfeifer, ${ }^{\dagger}$ Eve Melanie Reiter, ${ }^{\ddagger}$ Julio J. Cordero, ${ }^{\ddagger}$ and \\ Julie Dangremond Stanton** \\ 'Department of Plant Biology and "Department of Cellular Biology, University of Georgia, Athens, \\ GA 30602
}

\begin{abstract}
Self-advocacy is linked to the success and retention of students with disabilities in college. Self-advocacy is defined as communicating individual wants, needs, and rights to determine and pursue required accommodations. While self-advocacy is linked to academic success, little is known about how students with disabilities in science, technology, engineering, and mathematics (STEM) practice self-advocacy. We previously developed a model of self-advocacy for STEM students with attention-deficit/hyperactivity disorder (ADHD) and/or specific learning disabilities (SLD). Here, we use this model to examine what factors support or hinder self-advocacy in undergraduate STEM courses. We conducted semistructured interviews with 25 STEM majors with ADHD and/or SLD and used qualitative approaches to analyze our data. We found internal factors, or factors within a participant, and external factors, the situations and people, described by our participants, that influenced self-advocacy. These factors often interacted and functioned as a support or barrier, depending on the individuals and their unique experiences. We developed a model to understand how factors supported or hindered self-advocacy in STEM. Supporting factors contributed to a sense of comfort and security for our participants and informed their perceptions that accommodation use was accepted in a STEM course. We share implications for research and teaching based on our results.
\end{abstract}

\section{INTRODUCTION}

Despite an overall increase in the number of students with disabilities enrolling in postsecondary education, students with disabilities remain underrepresented in science, technology, engineering, and mathematics (STEM) majors (National Science Foundation [NSF], 2019). The underrepresentation of students with disabilities in STEM majors is not due to a lack of interest in STEM. We know that students with disabilities are as likely as students without disabilities to initially pursue a STEM major; however, relatively few students will graduate with a STEM degree (Lee, 2011, 2014). The reasons relatively few students with disabilities graduate from STEM majors are not clear. Students with disabilities, regardless of major, encounter many barriers in college. By developing our understanding of these barriers, we can begin to address and mitigate the barriers students with disabilities experience, leading to increased representation of students with disabilities in STEM.

One of the most profound barriers students with disabilities in college encounter is the shift in legislation guiding the accommodation process (Eckes and Ochoa, 2005). In high school, educational laws such as the Individuals with Disabilities Education Act mandate that school personnel identify and accommodate students with disabilities (Smith, 2001). The goal of these educational laws is academic success of students with disabilities. In college, two civil rights laws, the Americans with Disabilities Act
Stanley M. Lo, Monitoring Editor Submitted Jun 2, 2020; Revised Dec 28, 2020; Accepted Jan 27, 2021

CBE Life Sci Educ June 1, 2021 20:ar17 DOI:10.1187/cbe.20-06-0107

*Address correspondence to: Julie Dangremond Stanton (stantonj@uga.edu).

(c) 2021 M. A. Pfeifer et al. CBE-Life Sciences Education @ 2021 The American Society for Cell Biology. This article is distributed by The American Society for Cell Biology under license from the author(s). It is available to the public under an Attribution-Noncommercial-Share Alike 3.0 Unported Creative Commons License (http://creativecommons.org/licenses/ by-nc-sa/3.0).

"ASCB®" and "The American Society for Cell Biology $\circledR^{\prime \prime}$ are registered trademarks of The American Society for Cell Biology. 
and Section 504 of the Rehabilitation Act of 1973 require students themselves to take sole responsibility for their own accommodations (Eckes and Ochoa, 2005). The purpose of these civil rights laws is equal access to educational opportunities. The differences in these laws becomes important, because for many students with disabilities, college is the first time they have been responsible for their own accommodations, which can lead to difficulty in accessing and using them (Hadley, 2007; Getzel and Thoma, 2008). Understanding the factors that promote or hinder students from using their accommodations is needed to inform development of university policies, classroom pedagogies, and other practices that support retention of students with disabilities in STEM.

\section{Self-Advocacy}

While accessing and using accommodations in college can be challenging, many students with disabilities do implement accommodations effectively in their courses. Accessing and using accommodations in college is related to self-advocacy (Hadley, 2007; Getzel and Thoma, 2008; Dunn et al., 2012; Pfeifer et al., 2020). Self-advocacy is defined as "the ability to assertively state wants, needs and rights, determine and pursue needed supports" and to obtain and evaluate the needed support with the ultimate goal of conducting affairs independently (Martin and Marshall, 1995; Izzo and Lamb, 2002, p. 6). Self-advocacy is linked to higher grade point averages and increased graduation rates and is considered to be essential in the overall success of a student with a disability in college (Janiga and Costenbader, 2002; Hadley, 2007; Getzel and Thoma, 2008; Lombardi et al., 2011; Kinney and Eakman, 2017; Kreider et al., 2018). Enhancing self-advocacy is a promising way to reduce attrition of students with disabilities from STEM majors, considering the link between self-advocacy and success (Lee, 2011; Dunn et al., 2012).

Current research indicates that STEM courses can be challenging places to practice self-advocacy. STEM courses possess specific barriers in terms of content, including the informational materials required or instructional approaches used to participate or understand topics taught in a STEM course, and climate, including the quality and the nature of interactions in the course, for students with disabilities (Ofiesh, 2007; Hedrick et al., 2010; Isaacson et al., 2011; Isaacson and Michaels, 2015; Dunn et al., 2012; Moon et al., 2012; Tuosto et al., 2020). For example, a recent systematic literature review found the adoption of universal design for learning, a principle touted to be one of the best ways to ensure accessible course content, is minimal in college STEM courses (Schreffler et al., 2019). Furthermore, STEM students with disabilities may be less likely than their counterparts in other majors to use accommodations in their courses, and accommodation use varies by type of disability (Lee, 2011, 2014; Newman et al., 2011). For instance, students with learning disabilities are less likely than students with other types of disabilities to use accommodations in their courses (Newman et al., 2011). The mechanisms contributing to these phenomena are not yet fully characterized. However, it is proposed that students in STEM majors experience more barriers accessing accommodations than their non-STEM counterparts (Lee, 2011, 2014). Thus, undergraduate STEM courses likely represent a context in which students with learning disabilities experience issues practicing self-advocacy in the face of many factors that can function as barriers to learning and inclusion.
Although self-advocacy is recognized as important for success in college, our understanding of self-advocacy is still developing. Self-advocacy was originally derived from self-determination theory for people with disabilities (Test et al., 2005; Wehmeyer et al., 2003). A conceptual framework for self-advocacy was developed, which demarcated self-advocacy as a separate construct from self-determination (Test et al., 2005). The original self-advocacy framework was developed based on meta-analysis of existing research related to self-advocacy at that time, along with the input of self-advocacy stakeholders. Research included in the analysis varied in terms of context and participant characteristics. Once this framework was developed, it was not empirically tested to determine if, and to what degree, the framework explained the self-advocacy experiences of college students with disabilities. Many of the subsequent studies of self-advocacy in college students with disabilities used this framework without first determining whether the framework applied to their target populations. This is problematic because experiences of disability are not universal. For example, the experience of someone with a physical disability is much different from the experience of an individual with an invisible, or non-apparent disability (Daly-Cano et al., 2015; Vaccaro et al., 2015). Additionally, the climate a student with a disability encounters in college is known to influence that student's perceptions of acceptance, which likely influences self-advocacy (Hedrick et al., 2010; Stodden et al., 2011; Harbour and Greenberg, 2017). In sum, existing self-advocacy research may be missing or overemphasizing aspects of self-advocacy that are not relevant to particular groups of college students with disabilities in certain academic contexts, such as STEM.

Because self-advocacy is considered to be essential in the success and retention of college students with disabilities, we sought to study self-advocacy within the context of undergraduate STEM courses. We previously conducted an empirical study to test and revise the existing conceptual model of self-advocacy, based on the experiences of STEM majors with attention-deficit/hyperactivity disorder (ADHD) and/or specific learning disorders (SLD), also referred to as specific learning disabilities (Pfeifer et al., 2020). We decided to study self-advocacy in this group of students, because ADHD and SLD are two examples of a non-apparent disabilities, they are both common in college students, they often co-occur, and they share many similar features, although they are distinct disability types (Wolf, 2001; Raue and Lewis, 2011; DuPaul et al., 2013; Pham and Riviere, 2015; Budd et al., 2016). ADHD is divided into two major subtypes, predominantly inattentive and predominantly hyperactive/impulsive (American Psychiatric Association, 2013). A feature of ADHD predominantly inattentive is experiencing difficulty in remaining focused throughout daily life, while a feature of ADHD predominantly hyperactive/impulsive is extreme restlessness that may appear as intrusive behaviors, for example, excessive talking (American Psychiatric Association, 2013). SLD are made of three major subtypes, impairment in reading (dyslexia), impairment in written expression (dysgraphia), and impairment in mathematics (dyscalculia; American Psychiatric Association, 2013).

From our previous in-depth qualitative analysis, we found that self-advocacy for students with ADHD and/or SLD (ADHD/ SLD) in STEM was more complex than posited in the original self-advocacy framework (Pfeifer et al., 2020). In our previous 


\section{Self-advocacy in undergraduate STEM courses}

\begin{tabular}{|c|c|c|c|}
\hline Knowledge & Beliefs & Behaviors & \\
\hline Knowledge of self & View of disability & Communication & \\
\hline Knowledge of rights & Agency & Leadership & $\begin{array}{c}\text { and retention } \\
\text { in STEM }\end{array}$ \\
\hline $\begin{array}{c}\text { Knowledge of } \\
\text { accommodations }\end{array}$ & & Filling gaps & \\
\hline $\begin{array}{c}\text { Knowledge of } \\
\text { STEM learning contexts }\end{array}$ & & & \\
\hline
\end{tabular}

FIGURE 1. Our guiding model of self-advocacy for students with ADHD and/or SLD in undergraduate STEM courses. Each component of the self-advocacy model is defined in Table 1 . These components are aspects contributing to self-advocacy in undergraduate STEM courses. Knowledge, beliefs, and behaviors are not intended to be linear, that is, it is not yet clear whether knowledge leads to beliefs which lead to behaviors. Communication is bolded, because it is essential for self-advocacy. One possible product of self-advocacy is accommodation use in a STEM course. Self-advocacy likely enhances academic success and retention of students with ADHD/SLD in STEM majors (arrow and round-edged box). Figure modified from Pfeifer et al. (2020).

study, we revised the original framework to develop our model of self-advocacy. We use this model to define self-advocacy in our current study (Figure 1). Both studies analyze data collected from the same participants. In this study, we examine how the contextual factors of our participants influence the components of self-advocacy from our model.

In our model, self-advocacy is composed of self-advocacy knowledge, self-advocacy beliefs, and self-advocacy behaviors. Self-advocacy knowledge involves knowledge of self; rights, accommodations, and the process to obtain them; and STEM learning contexts. Self-advocacy beliefs include view of disability and agency, the belief that students with a disability are responsible for their own accommodations and success in college. Self-advocacy behaviors encompass communication, which is required for self-advocacy, filling gaps, and leadership. Filling gaps are the actions students take to mitigate a perceived limitation in either their formal accommodations or in the instructional practices used in a STEM course. Each part of our model of self-advocacy is defined in Table 1. In our model, we see accommodation use as one possible manifestation of self-advocacy that can enhance the academic success of students with ADHD/SLD, leading to increased retention in STEM majors.

\section{Theoretical Framework}

Our study is also guided by a broader theoretical framework, the social model of disability (Berghs et al., 2016; Haegele and Hodge, 2016). We selected this framework because it offers a clear conceptualization of disability and how social contexts, such as undergraduate STEM courses, contribute to the formation of disability. The social model of disability separates impairment from disability. Impairments are biological differences, such as ADHD/SLD. Disability is the hardship that arises within a context due to societal expectations of an individual with an impairment. The social model of disability posits that an impairment does not equate to disability unless a societal expectation makes the impairment tangible. For example, a student with ADHD/SLD may not experience that impairment as a disability until they encounter an expectation in a STEM course that makes the impairment evident. One example of such an expectation could be completing a written exam within a relatively limited amount of time. If this type of expectation causes hardship, the student now experiences disability. From the perspective of the social model, a biological difference does not need to be "cured" to address disability; rather, changes to the social context can be made. The other reason we used the social model of disability is because self-advocacy can mediate the relationship between impairment, disability, and the social context (Goodley, 1997). That is, individuals with an impairment can engage in self-advocacy to improve their own conditions within a social context and mitigate hardship due to disability. Thus, the social model of disability empowers individuals with impairments to practice self-advocacy.

Throughout our paper, we use person-first language, which purposefully emphasizes an individual and not their disability to preserve human dignity (Dunn and Andrews, 2015). We acknowledge that person-first language is not always the preferred terminology of all individuals with disabilities (Sinclair, 2013; Dunn and Andrews, 2015). As reviewed in Dunn and Andrews (2015), some people feel that using person-first language emphasizes disability as a negative aspect of human experience, while other people prefer identity-first language, because they do not view disability to be shameful and embrace this characteristic as part of themselves. We use person-first language here for two reasons: 1) person-first language was used by most of our participants when discussing their own disabilities and 2) person-first language remains the preferred style guideline by many professional associations, such as the American Psychiatric Association.

\section{Current Study}

In our current study, we expand on our prior work by characterizing the factors that supported or hindered self-advocacy for 25 students with ADHD/SLD who were STEM majors. By conducting this research, we aim to enhance the self-advocacy experiences of students with ADHD/SLD in undergraduate STEM courses as a mechanism for retaining students with disabilities in STEM. In our current study, we investigated the following research question: What factors influenced the 
self-advocacy of our participants in undergraduate STEM courses?

\section{METHODS \\ Context of Study}

This study was conducted at a public university in the southeastern United States with very high research activity. Our study was approved for exempt status by the University of Georgia Institutional Review Board (STUDY00004663). All participants in our study were STEM majors who were registered with the university's Disability Resource Center (DRC) and eligible to receive services for either ADHD and/or SLD (ADHD/SLD) as their primary or secondary condition. Given the similar nature of ADHD and SLD (see Introduction), we reasoned these groups of students would have similar self-advocacy experiences. We recruited students who were STEM majors, as opposed to life science majors specifically, although life science majors outnumber other STEM majors at the institution where data collection took place. This work is a component of a larger study about self-advocacy of students with ADHD/SLD in undergraduate STEM courses. For additional analysis of these data, please see Pfeifer et al. (2020).

\section{Overview of the Accommodation Process for Participants}

The accommodation process at the institution where data collection took place is an important part of this study's context. Students submitted official documentation of their disabilities to the DRC to be reviewed and approved. Each student was then assigned to a specific DRC coordinator and asked to schedule an initial accommodation meeting. In the initial accommodation meetings, students and their DRC coordinators agreed to the accommodations the students would be eligible to request in their courses, and the DRC coordinators explained how the students would request accommodations using an online accommodation system. All official accommodation letters were sent to instructors through the online accommodation system, once the students selected the accommodation(s) they would use in a particular course. Instructors then acknowledged receipt of official accommodation letters. Students were only required to meet with their DRC coordinators once during their college careers, unless the students initiated further meetings or communication.

\section{Data Collection}

Data were collected using semistructured interviews and a short demographic survey. Participant demographics are summarized in Table 2. Participants were recruited in partnership with the university's DRC to preserve confidentiality of all registered students in Fall 2018 and Spring 2019. We previously described our detailed methods, including participant recruitment, and development of our interview protocol (Pfeifer et al., 2020). DRC coordinators forwarded a standard recruitment email to all eligible participants on their caseloads, and students interested in participating in the study then contacted the research team directly. We used this approach because we reasoned students currently registered with the DRC would be more likely to engage in self-advocacy at the time of data collection. We see registering with the DRC as a prerequisite for use of accommodations in STEM courses, which is one prominent way a student demonstrates self-advocacy (Figure 1). However, use of accommodations is not the only manifestation of self-advocacy, and it is possible that students with ADHD/SLD not registered with the DRC also possess self-advocacy, although more research is needed to better understand those unique experiences.

A copy of the interview questions related to this study is available in Supplemental File 1. Each participant was compensated \$20 for completing an interview, and all participants provided written consent. The average length of each interview was 80 minutes. Interviews were audio-recorded and professionally transcribed, and the resulting transcripts were checked to ensure accuracy before coding.

\section{Qualitative Data Analysis}

Data were analyzed by a diverse research team using MaxQDA 2018. Our team consisted of one or more researchers who was/ were a STEM major with ADHD/SLD, a researcher with 5 years previous work experience in a DRC at a different university, and a current undergraduate STEM instructor. Coder identities and roles are left anonymous in an effort to preserve confidentiality. We embarked upon our analysis by open coding, also called initial coding (Saldaña, 2015). The goal of our open-coding process was to consider the entirety of our data and begin identifying the nuances and processes related to self-advocacy. Individual researchers open coded a subset of the interviews, wrote analytic memos following each interview, and then met to discuss emergent ideas as a team. We identified five interviews (i.e., $20 \%$ of our data) that represented the range of our data to begin development of our codebook.

Codebook development and subsequent analysis employed the constant comparison method to ensure rigor in our coding (Charmaz, 2006; Fram, 2013). Our deductive codes originated from Test's framework of self-advocacy: knowledge of self, knowledge of rights, communication, and leadership (Test et al., 2005). We developed inductive, or emergent, codes based on the experiences of our participants. Three members of our research team proposed codes after reading five interviews representing the range of our data. We refined these codes through discussion and careful consideration of which proposed codes aligned with our research questions. We further refined these codes by analyzing another subset of the interviews and meeting to add, remove, or redefine our existing codes. We then coded interviews individually and subsequently met as a team to discuss how each researcher applied the codes. Through these iterations, our codebook stabilized. Two researchers then coded all 25 interviews using our stabilized codebook (available in Supplemental File 2). The researchers met after coding sets of three to four interviews to discuss coding and to resolve any coding differences. In these meetings, coding differences were resolved, and data were recoded as needed to code to consensus.

We examined first-cycle codes during the second cycle. We relied on pattern and axial coding to identify themes within our data. Pattern coding involves organizing similar data into themes, and axial coding involves identifying code attributes and determining how these attributes relate (Saldaña, 2015). During our second-cycle coding process, one researcher took the lead in proposing second-cycle codes to the other researchers. We discussed these second-cycle codes and resolved any disagreements. Feedback on our emergent 
TABLE 1. Definitions of self-advocacy components from our model of self-advocacy for students with ADHD and/or SLD (ADHD/SLD) in undergraduate STEM courses

\begin{tabular}{|c|c|}
\hline Self-advocacy component & Definition \\
\hline Knowledge of self ${ }^{a}$ & Knowledge of self is an awareness an individual has about their strengths and weaknesses as a learner with a disability. \\
\hline Knowledge of rights ${ }^{\mathrm{a}}$ & $\begin{array}{l}\text { Knowledge of rights is an awareness of an individual's "rights as a citizen, as an individual with a disability, and as a } \\
\text { student receiving services under federal law" (Test et al., 2005, p. 50). }\end{array}$ \\
\hline $\begin{array}{l}\text { Knowledge of STEM } \\
\quad \text { learning contexts }\end{array}$ & $\begin{array}{l}\text { Knowledge of STEM learning contexts is an understanding that the learning environment experienced by a student } \\
\text { with ADHD/SLD in undergraduate STEM courses influences their accommodation needs. STEM learning } \\
\text { contexts discussed by our participants include: STEM lecture courses, laboratory courses, laboratory sections of } \\
\text { STEM courses, discussion or recitation sections of STEM courses, online STEM courses, independent research } \\
\text { experiences in academic labs, and internships with local STEM companies. }\end{array}$ \\
\hline $\begin{array}{l}\text { Knowledge of } \\
\quad \text { accommodations }^{\mathrm{b}}\end{array}$ & $\begin{array}{l}\text { Knowledge of accommodations is understanding: } \\
\text { 1. the accommodations that are available to a student with ADHD/SLD in college, and } \\
\text { 2. how the accommodation process in college works, including knowledge of the student role, the DRC } \\
\text { coordinator role, and the instructor role. }\end{array}$ \\
\hline Communication $^{\mathrm{a}, \mathrm{c}}$ & $\begin{array}{l}\text { Communication for the purpose of self-advocacy involves "negotiation, assertiveness, and problem-solving in a } \\
\text { variety of situations" (Test et al., 2005, p. 50). }\end{array}$ \\
\hline Leadership ${ }^{\mathrm{b}}$ & $\begin{array}{l}\text { Leadership involves taking action for others with diagnosed disabilities to overcome stigma, and advocating for } \\
\text { peers without formally diagnosed disabilities to be tested to receive accommodations. }\end{array}$ \\
\hline Filling gaps ${ }^{b}$ & $\begin{array}{l}\text { Filling gaps is taking an action to mitigate a perceived limitation in either formal accommodations, or in the } \\
\text { instructional practices used in a STEM course. }\end{array}$ \\
\hline View of disability ${ }^{\mathrm{b}}$ & $\begin{array}{l}\text { View of disability is a belief a student holds about their own disability, and their perceptions of how STEM instruc- } \\
\text { tors and peers view disability and accommodation use in the context of undergraduate STEM courses. }\end{array}$ \\
\hline Agency ${ }^{\mathrm{b}}$ & Agency is a belief that a student with a disability is responsible for their own accommodations and success in college. \\
\hline
\end{tabular}

Indicates a definition from Test et al. (2005).

'Indicates a definition from Pfeifer et al. (2020).

cCommunication is bolded because it is required for self-advocacy.

results was gathered from our research team, and refinements were made to encompass all our perspectives. From our analysis, we identified the factors that supported or hindered self-advocacy for students with ADHD/SLD in undergraduate STEM courses. We organized these factors into a model to explain how self-advocacy is affected in undergraduate STEM courses.

\section{Trustworthiness of Study}

We sought to establish the trustworthiness of our study by using several techniques. We deliver detailed methods and provide our codebook in Supplemental File 2, highlighting our data analysis procedures so that readers may assess our processes (Krefting, 1991; Tracy, 2010; Richards and Hemphill, 2018). Throughout our study all researchers used research journals to provide an audit trail of our decisions and engaged in self-reflexivity by writing analytic memos as a check for individual researcher bias (Johnson, 1997; Saldaña, 2015; Richards and Hemphill, 2018). One particular strength of our study is the use of multiple researchers coding to consensus as a form of triangulation (Tracy, 2010; Olson et al., 2016; Richards and Hemphill, 2018). Coding to consensus by a diverse research team is a rigorous approach for analyzing complex constructs, such as self-advocacy (Olson et al., 2016; Richards and Hemphill, 2018; Stanton et al., 2019; Pfeifer et al., 2020). Importantly, our research team consisted of one or more members who was/were a STEM major with ADHD/SLD, which provided essential expertise into the lived experiences of our participants during firstand second-cycle coding (Vaccaro et al., 2015). Finally, we provide our readers with a consideration for transferability of our findings (See Limitations) (Krefting, 1991).

\section{RESULTS}

We identified factors that functioned as a support or as a barrier to the self-advocacy of our participants based on their experiences in undergraduate STEM courses. We considered self-advocacy to be supported when our participants described factors that encouraged or reinforced their self-advocacy behaviors. Conversely, self-advocacy was hindered when our participants described factors that discouraged or thwarted their self-advocacy behaviors or accommodation use. In our analysis, self-advocacy behaviors included communication, filling gaps, and leadership. We view accommodation use as one possible product of self-advocacy. Our participants described factors within themselves that influenced their own self-advocacy. We call these internal factors. Participants also shared with us how the situations and people they encountered as a student with ADHD/SLD in undergraduate STEM courses influenced their self-advocacy. We refer to these instances as external factors. Our data revealed how internal and external factors interact, and how these factors and interactions affected the self-advocacy of our participants.

\section{Internal Factors}

First, we describe how internal factors functioned as a support or as a barrier to the self-advocacy of our participants. Internal factors included: self-advocacy knowledge, self-advocacy beliefs, and identity. We describe data demonstrating how self-advocacy knowledge and self-advocacy beliefs support or hinder self-advocacy. We close our internal factors section by sharing data that illuminate the complexity of individual identity, and how this identity influenced the self-advocacy of our participants. All of our participants are represented by pseudonyms. Quotes have been lightly edited for clarity. Ellipses 
TABLE 2. Summary of participant demographic information ${ }^{a}$

\begin{tabular}{|c|c|}
\hline Participants $(n=25)$ & Number (\%) \\
\hline \multicolumn{2}{|l|}{ Gender } \\
\hline Female & $11(44 \%)$ \\
\hline Male & $14(56 \%)$ \\
\hline \multicolumn{2}{|l|}{ Race } \\
\hline White & $23(92 \%)$ \\
\hline Black or African American & $2(8 \%)$ \\
\hline \multicolumn{2}{|l|}{ STEM major } \\
\hline Life sciences & $13(52 \%)$ \\
\hline Engineering & $7(28 \%)$ \\
\hline Physical science & $2(8 \%)$ \\
\hline Mathematics & $2(8 \%)$ \\
\hline Computer science & $1(4 \%)$ \\
\hline \multicolumn{2}{|l|}{ Year in college } \\
\hline First year & $3(12 \%)$ \\
\hline Second year & $3(12 \%)$ \\
\hline Third year & $8(32 \%)$ \\
\hline Fourth year & $4(16 \%)$ \\
\hline Fifth year & $5(20 \%)$ \\
\hline Sixth year+ & $2(8 \%)$ \\
\hline \multicolumn{2}{|l|}{ Participant diagnoses } \\
\hline ADHD & $15(60 \%)$ \\
\hline SLD & $5(20 \%)$ \\
\hline ADHD and SLD & $5(20 \%)$ \\
\hline \multicolumn{2}{|l|}{ Time of official diagnosis } \\
\hline College & $8(32 \%)$ \\
\hline Before college & $17(68 \%)$ \\
\hline \multicolumn{2}{|l|}{ Type of high school attended } \\
\hline Public & $14(56 \%)$ \\
\hline Private & $11(44 \%)$ \\
\hline \multicolumn{2}{|l|}{ Other } \\
\hline Transfer students & $6(24 \%)$ \\
\hline First-generation students & $2(8 \%)$ \\
\hline Pell Grant recipients & $5(20 \%)$ \\
\hline
\end{tabular}

aThis table is modified from our previous publication Pfeifer et al. (2020), a Springer publication.

represent language removed from the participant's quote for brevity.

Self-Advocacy Knowledge. Self-advocacy knowledge is composed of knowledge of self, knowledge of rights, knowledge of accommodations, and knowledge of STEM learning contexts (Pfeifer et al., 2020; Figure 1). We define STEM learning contexts as the various learning environments undergraduate students encounter during their college careers as STEM majors. Our participants discussed their self-advocacy experiences in STEM lecture courses, laboratory courses, laboratory sections of a STEM course, discussion or recitation sections of a STEM course, online STEM courses, independent research experiences in academic labs, and internships with local STEM companies. In our previous study, we found that self-advocacy knowledge varied among our participants (Pfeifer et al., 2020). In this study, we sought to understand how self-advocacy knowledge supported or hindered self-advocacy beliefs and self-advocacy behaviors in undergraduate STEM courses.
We found that self-advocacy knowledge supported other aspects of self-advocacy when our participants displayed what we termed sufficient self-advocacy knowledge. Participants demonstrated sufficient self-advocacy knowledge when they explained how their knowledge of self, knowledge of accommodations, and knowledge of STEM learning contexts influenced their accommodation decisions, or decisions to discuss an accommodation issue with a STEM instructor. One participant, Mia, explained how her self-advocacy knowledge supports her self-advocacy, "I'm aware of what [accommodations] I need and I'm aware of where this disability affects me. So, why not [communicate that to my STEM instructors]?" Many participants displayed sufficient self-advocacy knowledge, and this knowledge supported their self-advocacy. When participants demonstrated sufficient self-advocacy knowledge, they were aware of how to procure accommodations in a variety of STEM learning contexts, including the laboratory section of a STEM course, and to troubleshoot accommodation issues that occurred during the course of the semester. They were also aware that if they found an accommodation no longer met their learning needs, they could communicate with their DRC coordinators to explore adjusting the ineffective accommodation. Although many of our participants demonstrated sufficient self-advocacy knowledge, some were still developing this knowledge.

We found examples of when insufficient self-advocacy knowledge hindered our participants' self-advocacy. Insufficient self-advocacy knowledge occurred when participants described that they were not aware that they could request adjustments to their accommodations if they found an accommodation inadequate. We also identified instances when participants held inaccurate ideas about the accommodation process that hindered their self-advocacy. One example of this came from Megan, who shared that she did not know how much information about her disability was included in the official notification letter sent to her STEM instructors by the DRC on her behalf:

I wish I knew what the DRC was sending [my STEM instructors] because I guess I've always assumed that they were being informed of what my disability is, and I would rather that be how it works.

Megan's assumption that her STEM instructors already knew what her disability was hindered her self-advocacy, because it caused miscommunication when she met one-on-one with her instructors, which could lead to confusion. Official accommodation letters sent to instructors do not disclose disability diagnoses. Megan described a time she misread an exam question and wanted to meet with her STEM instructor to talk about why she missed points on the exam. Because Megan thought her instructor knew she had dyslexia from the official notification letter, she assumed the instructor would understand why she misunderstood the question on the exam. Thus, Megan's insufficient self-advocacy knowledge hindered her self-advocacy.

Some participants also reported other inaccurate ideas about accommodations. Participants told us that accommodations were not available in online courses or summer courses and at smaller, two-year colleges. These were our participants' perceptions, and we do not know why our participants held these inaccurate ideas. We did inform these participants at the end of their interviews that students with ADHD/SLD are legally 
entitled to accommodations in these instances. Additionally, a few participants told us that they thought that the only way they could request accommodations was to directly disclose their exact disability diagnosis(es) to a STEM instructor in a one-on-one meeting. Several participants reported that they currently thought, or at one time earlier in their college careers had thought, accommodations were not available in the lab section of a STEM course. The inaccurate idea that accommodations are not available in lab sections of STEM courses was commonly expressed by students who had recently started college and participants who had recently started using accommodations for the first time in college.

During our analysis, it became apparent that self-advocacy knowledge was often tied to self-advocacy beliefs. Participants with sufficient self-advocacy knowledge tended to display beliefs about themselves that positively influenced self-advocacy, and participants still developing their self-advocacy knowledge tended to display beliefs that did not support their self-advocacy. We explain how self-advocacy beliefs functioned as both a support and a barrier for our participants in the next section.

Self-Advocacy Beliefs. Self-advocacy beliefs are composed of view of disability and agency. We define agency as a participant's belief that they are responsible for their own accommodations and success in college. Participants who tended to view their disability in a positive manner and demonstrate agency engaged in more self-advocacy, as we previously reported (Pfeifer et al., 2020). These participants appeared to be more willing to seek information about their disability or accommodations when they encountered a problem, which likely supported their development of self-advocacy knowledge. None of our participants displayed a positive view of disability with low agency.

Participants who tended to view their disability negatively or in a conflicted manner appeared to struggle to practice self-advocacy. Ryan explained that, in high school, he felt his disability was a "threat to being normal ... with my peers," and that he mainly used accommodations in college because his mom recommended it. He stated, "Technically, I have a disability, even though I'm kind of embarrassed about it." Ryan was a participant who appeared to still be developing sufficient self-advocacy knowledge, because he held many inaccurate ideas about the accommodation process. Other participants, like Aaron and Judd, also tended to view their own disability negatively, while several others appeared to be conflicted about their disability, and this view could also make self-advocacy challenging.

Participants who did not display agency appeared to struggle to engage in self-advocacy behaviors in their STEM courses. This was most evident in Dana, a sixth-year student, who was registered with the DRC but had never used accommodations in college. She stated that it took her several semesters to register with the DRC because she "kept forgetting." She further stated, "So yeah, ask the ADHD kid to go get accommodations. You know, my mom used to just do it [for me] when I was in high school." Dana appeared to still be developing her agency and was an example of someone who experienced major challenges in the transition from high school to college in terms of accommodations. Dana candidly stated that she had struggled in college because of her decision to not use accommodations. She expressed that she wished she had used accommodations sooner. Dana also held many inaccurate ideas about accommodations and the process to obtain them in college. Although Dana was still developing her knowledge of accommodations, she did display some self-advocacy behaviors, such as filling gaps, when she would ask her close friends to tutor her in her engineering courses.

Our data showed how self-advocacy knowledge and beliefs functioned as both a support and a barrier, depending upon the participant. We became curious as to what other internal factors influenced self-advocacy. We found that the identities of our participants were complex and that the facets of their identities affected their self-advocacy. We explain how the internal factors of identity related to the self-advocacy of our participants in the next section.

\section{Identity}

Participants reported that the intersectional nature of their identity (i.e., belonging to multiple groups traditionally underrepresented in STEM in terms of disability, gender, and race), could sometimes hinder their sense of comfort to engage in self-advocacy behaviors within their STEM courses. We acknowledge that we did not design any interview questions to determine how the intersectional nature of identity can also function as a support to self-advocacy. We hypothesize that these dimensions of identity can also function as a support, depending upon the context. We include these ideas because they emerged from our data and they point to the need for instructors to consider the intersectional nature of student identity in their teaching.

The Intersectionality of Disability, Gender, and Race in Undergraduate STEM Courses. Some of our participants described how their perceptions of exclusion from STEM were exacerbated by the intersectional nature of their identities.

Two participants, Cassie and Dana, shared that identifying as female in a male-dominated STEM field hindered their self-advocacy. When we asked Cassie, who is a female physics major, what factors prevent her from communicating for the purpose of self-advocacy, she responded, "Just in general I get intimidated by specifically older men in an authoritative position, which is the majority of my professors." Cassie explained that she already found it challenging to talk about her disability and accommodation use in general, and this discomfort was amplified because she is also female. For Cassie it was more challenging to talk to her STEM instructors because they are mostly men. Another participant, Dana, explained that as a female engineering major, she does not want her male peers to know she uses accommodations, because she thinks they will see it as a weakness. "Guys ... they're so judgmental in engineering. They think every girl's dumb and they treat you as such." Dana expounded that one reason she has never used accommodations in college, although she is registered with the DRC, is because she does not want her peers to find out she has ADHD.

One participant, Carter, shared that the intersectional nature of his identity can complicate his self-advocacy. Carter, an African-American male student with ADHD at a predominantly white university, reported that he perceives his peers to think less of him. When we asked him why, he stated, 
Being African American ... is very, very, very hard in undergraduate STEM courses because these people, they already think less of you regardless ...Then for you to be going and getting accommodations ... that just puts the icing on the cake.

Carter spoke to the intricacy of his identity. He felt that his peers already thought less of him because of his racial identity, and this negative feeling was magnified because he also has ADHD and uses accommodations in his STEM courses. Carter revealed later in the interview that he rarely, if ever, talks about having $\mathrm{ADHD}$ and using accommodations with his peers.

We found the internal factors described by our participants to be complex and often interconnected. Participants explained to us how the situations they encountered as students with ADHD/SLD influenced their own self-advocacy knowledge and self-advocacy beliefs and contributed to the formation and understanding of their own identities within a STEM context. In the following section, we demonstrate how external factors supported or hindered self-advocacy based on the experiences of our participants.

\section{External Factors}

Our participants shared a myriad of situations and interactions with people, which we call external factors, that encouraged, discouraged, or in extreme cases prevented self-advocacy behaviors and accommodation use in their undergraduate STEM courses. External factors included other individuals, the logistics of accommodation implementation, classroom environment, and the norms and values of the STEM discipline. Throughout this section, we present data demonstrating how an external factor functioned as a support or as a barrier to the self-advocacy of our participants. We emphasize that these data are from the point of view of the participants and that our participants' perceptions may or may not reflect the reality of the situation. Yet these perceptions influenced self-advocacy. We begin by examining how other individuals supported or hindered self-advocacy.

\section{Other Individuals}

During the interview, we asked participants who, if anyone, helped them with accommodations in college. Our participants named several individuals, including peers, family, DRC coordinators, and other professionals who helped them with accommodations in college. When we asked our participants to describe the type of help these individuals provided, we found our participants described two major forms of self-advocacy support: 1) information and advice related to self-advocacy and 2) emotional support. Information and advice helped participants develop self-advocacy knowledge and gain skills to more effectively practice self-advocacy in their undergraduate STEM courses. Emotional support encouraged positive self-advocacy beliefs and promoted positive perceptions of identity. Although other individuals supported the self-advocacy of our participants, many participants discussed situations in which other individuals hindered their self-advocacy. For instance, some participants explained how negative comments from peers functioned as a barrier to their self-advocacy. We explain in the following sections how peers supported or hindered the self-advocacy of our participants. Because families and other professionals were not directly involved in self-advocacy experiences within an undergraduate STEM course (i.e., they were not physically present in the classroom), we report these results in Supplemental File 3.

Peers as a Support. Participants in our study described how their peers supported them in college as a student with ADHD/ SLD. In our analysis, we found that peers supported the self-advocacy of our participants by engaging in meaningful conversations about disability and accommodation use. These types of conversations helped our participants feel comfortable discussing their disability or accommodation use with other people. For example, Tyler described how his friends helped him find humor in a potentially unpleasant situation with an ignorant peer. "Well, what happened was this kid didn't know what dyslexia was and he thought it was color blindness. So, now, my friends ... if I spell something wrong, they'll be like, 'Oh you're so colorblind.' So we usually joke about it." Here, Tyler, felt a sense of comradery with his friends, because they shared an inside joke. We interpreted this as a sign he felt comfortable talking to his friends about his specific learning disability in reading.

We also found that other participants, like Jake, shared that their peers responded positively when they disclosed their disability, "As soon as they found out, they were all asking me questions and getting involved." Jake described that many of his friends are human development majors, and they wanted to know more about his experiences as a student with ADHD. Other participants, like Ryan, explained that he felt like he needed to hide his disability from most of his peers. However, the one time he did talk to his friends about it, he described it as "comforting" and a "great feeling," because they "supported me." These examples underscored that peers supported self-advocacy by making our participants feel like they can talk openly about having a disability.

Our participants also shared more specific examples of how their peers supported their self-advocacy. For some participants, their peers encouraged them to use accommodations in their STEM courses, because they could see that the participants would benefit from using them. One of our participants, Kendra, described a time when her peers supported her self-advocacy directly, by helping her figure out who she should communicate with when she forgot to schedule a final exam at the DRC her freshman year of college.

The night before I was panicking. The day of I was panicking, freaking out, and my friends helped me figure out what to do. They were like, "Here, you should go and talk to the DRC office, even if you can't get your accommodations. And then if you do get them, that's great. And if you don't get them, then you should go to your instructor."

Kendra's friends supported her self-advocacy, because they helped her make a plan to deal with an accommodation issue. Interestingly, we found that our participants especially valued the support of peers who have the same disability and accommodations. Kirsten expressed that she appreciates being part of an undergraduate research lab, because many of her peers also have ADHD. She stated, 
There's actually a small group of us that all have ADHD ... we're all on the same medication, and we all do the same things, so we talk and we vent to each other a lot about any frustrations we have ... It's kind of nice to have that there.

Kirsten found that her peers with ADHD understand what it is like to have ADHD as a student who is a STEM major and that this peer group is a support for her self-advocacy. Heath reported receiving support for self-advocacy from his roommate who also has ADHD. Heath and his roommate reminded each other to schedule exams at the DRC and preferred to study together, because they can both study for several hours at a time without taking any breaks. Other participants, like Opal, reported that she studies in a group with two other people who also take extended-time exams at the DRC. Opal stated that she feels better about going to the DRC to take her exams, because she can go with her peers. She explained that having friends who also use accommodations is a support for self-advocacy, because it helps her overcome negative comments from other peers who do not believe using accommodations is fair. "I mean, those negative comments are always around, but it's not bothersome because I have two friends who also go to the DRC to take exams." Opal felt more comfortable in using her own accommodations, because her friends use accommodations too, and this supports her self-advocacy. While our participants shared many examples of how their peers supported their self-advocacy, there were instances when peers hindered self-advocacy.

Peers as a Barrier. Several participants described interactions with their peers that left them feeling that their peers questioned their use of accommodations in their STEM courses or did not understand their disability. Kirsten stated, "I don't think [most of my peers] take people that test at the DRC particularly seriously, which is sometimes frustrating. I just regularly get called 'lucky' for having [accommodations] ... I'm like that's not really how it works." Another participant, Oakley, described when a peer in her STEM course implied that using extra time on exams gave Oakley an unfair advantage.

She said [students who use accommodations] are not on the same playing field as everyone else [because they use accommodations]. I said, "No, I actually have this diagnosed thing. Here's a report on it." And she was like, "Well, yeah, a lot of people get diagnosed with ADHD."

Opal had a similar experience as Oakley. Opal explained that her peer even went so far as discrediting the grade Opal earned on an exam because Opal used extra time. Opal's peer stated to a group of classmates, "Oh, she gets extra time. No wonder she got a better grade than everyone." These types of negative comments made participants reluctant to discuss their disability or accommodation use openly with their peers.

For many participants, inadvertently revealing their disability or their accommodation use to their peers was a substantial concern. For two participants, Dana and Aaron, this concern was so elevated, they declined to use accommodations in their STEM courses at the time of the interview. Dana, an engineering major who has never used accommodations in college, shared why she worries about her peers knowing she uses accommodations in her STEM courses:
My peers might be my coworkers ... I could be in a job with them, and they know my habits ... You realize you not only have to impress the professor, you realize you have to impress your peers, too, because they're watching you more so than the professors are.

Within Dana's major, upper-division students will often be placed together at internships with local companies, and these internships often lead to future employment. Dana explained that she does not want her peers to know that she qualifies for accommodations, because she thinks that if they know, it might prevent her from finding a job. Another participant, Aaron, who at one point felt comfortable using his accommodations, shared that he now felt self-conscious in his upper-division math classes. This unpleasant feeling influenced his decision to opt out of accommodations in these courses.

I experienced like shame, not directly, but just ... internally from my peers. Because once you get into like a higher-level math class, you start seeing the same people again, and I always felt self-conscious of not being there in class on the day of the exam.

Aaron further explained that one of his peers previously convinced him that using accommodations was unfair, and now he thinks all his peers believe using accommodations is unfair, even if they do not say so directly to Aaron. This perception of peer disapproval is a barrier for Aaron, because he stopped using accommodations in his STEM courses.

Some of our participants described defending the use of accommodations to their peers who say accommodations are unfair. Carter stated, "They can think what they want, but I'm still going to do what I need to be a better student." Carter and some other participants responded to negative peer attitudes regarding disability and accommodation use with resilience. This resilience was tied to positive self-advocacy beliefs. Besides peers, the logistics of accommodation implementation influenced the self-advocacy of our participants.

\section{Logistics of Accommodation Implementation}

During the interview, we asked participants to describe a time they decided not to use accommodations in a STEM course and to share the rationale for such a decision. These data revealed that the way an accommodation is administered influenced the accommodation decisions of our participants. We begin by sharing how accommodation implementation supported the self-advocacy of our participants and transition into instances in which self-advocacy was hindered.

Logistics of Accommodation Implementation as a Support. The way in which accommodations were implemented supported the self-advocacy of our participants. For instance, a proportion of our participants began using accommodations in college at a time when their university was still using a paperbased system for accommodations. In this system, after the initial accommodation meeting with a DRC coordinator, students were required to bring their accommodation notification letters to their STEM instructors in person. These participants acknowledged that the former paper system "forced" them out of their comfort zone, because they had to talk to their STEM instructors. 
However, they reported that they feel much less stress using the current online accommodation system, because they have the choice of face-to-face communication with their STEM instructors. Participants who did not experience the paper-based system also reported that the online accommodation system encourages their accommodation use, because it does not require them to talk to their STEM instructors in person. This is one example of how the logistics of accommodation implementation was reported by our participants to support their self-advocacy. While there were ways in which accommodation implementation functioned as a support, our participants also explained how the logistics of an accommodation hindered their self-advocacy.

Logistics of Accommodation Implementation as a Barrier. We found that the details of how an accommodation was implemented hindered the self-advocacy of some participants. The cost of diagnostic testing to initially register with the DRC was a logistical barrier encountered by some participants in our study. However, these participants overcame this barrier with help from their families and, in some cases, scholarships. In the following section, we focus on aspects of the accommodation process after initial registration with the DRC that functioned as a barrier.

We found that our participants discussed how the logistics of their note-taking and extended-time accommodations compromised their sense of confidentiality. Some participants explained that they forgo use of their note-taking accommodations because of the logistics in finding a peer note-taker. In these cases, participants often have to remind their STEM instructors to make an announcement to the class to identify a peer who would provide a copy of their notes to the DRC for participant access. Many of our participants were concerned that the STEM instructors would reveal their identities in the class announcement or later to the peers who agreed to provide notes. These participants often expressed great concern about their peers finding out they use accommodations in their STEM courses. A perceived loss of confidentiality, or the potential for loss of confidentiality, also influenced participants taking extended-time exams at the DRC. Several participants described opting out of their extended-time accommodations to ensure their peers do not notice their absence from the classroom on exam day.

Besides issues of confidentiality, our participants explained how other logistical aspects of extended-time accommodations hindered their self-advocacy. Some participants explained that they decided not to use accommodations on exam day because they perceived a disparity in the information they could access from the instructor during the exam. For instance, several participants explained that when they take an exam at the DRC, they sometimes do not have all the information they need to complete the exam. One example of this was during a chemistry exam, the exam provided to the DRC did not have a periodic table, because the instructor planned to project a copy of the periodic table in the classroom. Our participants further reported that they would opt of out of their exam accommodations so they could ask the instructor questions in person in the classroom on exam day.

These data establish that our participants considered how accommodations were implemented, and the details of this implementation process influenced their self-advocacy. We also found that our participants were especially perceptive of the classroom environment in their STEM courses. In the following section, we describe how the classroom environment of an individual STEM course supported or hindered our participants' self-advocacy.

\section{Classroom Environment}

Our participants reported that their self-advocacy could be supported or hindered by the classroom environment in a single STEM course. We found that our participants' perceptions of the classroom environment were substantially influenced by STEM instructors and the policies STEM instructors chose to put in place in their classrooms. In this section, we present data showing how STEM instructors functioned as a support or a barrier to the self-advocacy of our participants.

STEM Instructors as a Support. In our study, participants shared their perceptions of their STEM instructors and described interactions they have had with their STEM instructors that positively influenced their self-advocacy. We found that participants designated STEM instructors to be supportive of self-advocacy when they perceived their STEM instructors to be open to listening to their students. Our participants also shared that STEM instructors supported their self-advocacy by directly encouraging accommodation use in their courses. For a few participants, their STEM instructors were the people who first encouraged them to use accommodations in college. Jake explained that his calculus instructor was the person who connected him to the DRC first, because "she realized that during the problems on the exam I was getting distracted." His STEM instructor directly supported his self-advocacy by informing Jake accommodations were available to him in college and by helping him start the accommodation process with the DRC. Other participants besides Jake also described instances when their STEM instructors walked them over to the DRC to help them start the accommodation process early in their college careers.

A few participants shared that their STEM instructors supported their self-advocacy by directly affirming use of accommodations in their course. Kendra shared that STEM instructors supported her self-advocacy by inviting her to contact them if any accommodation issues arose during the semester. For instance, Kendra reported that some STEM instructors will say, "If there's anything you need, for me to help you, please just let me know." Kendra continued,

I've only had a teacher say that to me a couple of times, but it's always kind of relieving ... It's just nice to hear, okay yeah, they'll help me out ... I had a teacher do that recently, and it was like oh my gosh, thank you so much. You don't understand what this means.

Kendra, and other participants like Aaron, felt extremely concerned about their instructors' perceptions of them. Aaron explained that one of his STEM instructors encouraged his self-advocacy by assuring Aaron that his use of accommodations did not make him a "lesser student." By encouraging students to use accommodations in their courses and to contact them if an accommodation issue occurred, instructors supported self-advocacy. 
We found our participants especially appreciated when their STEM instructors planned to provide accommodations for in-class quizzes. For example, Opal described that in one of her STEM courses, her instructor had already approved her accommodation request for extended-time exams proctored at the DRC. When the STEM instructor proctored an in-class quiz, he communicated with Opal to explain that he already had a plan in place for her to take in-class quizzes in a way that allowed Opal to take the quiz in-class and still use extended time in a confidential manner. Opal found this helpful, because she did not have to ask him again for extra time on the in-class quizzes, as she sometimes does in other courses.

Our participants also shared that, when their STEM instructors follow up with them about their accommodations, it supports their self-advocacy, because it shows that the instructors care about their success in their courses. For example, some participants said that when their instructors ask them (in a way that preserves their confidentiality) about issues they may have experienced when taking an extended-time exam at the DRC, it supports their self-advocacy. One participant, Mia, reported a unique way one of her former STEM instructors helped her develop self-advocacy. Mia shared that, early in her college career, one of her STEM instructors initiated a conversation about an upcoming exam Mia would take at the DRC. The STEM instructor asked Mia if she had any questions for the instructor about the upcoming exam, because Mia would take the exam off-site at the DRC, and the instructor would not physically be there to answer questions about the exam. This conversation prompted Mia to ask her instructor about the details she needed to know when she took the exam, for example, whether she needed a Scantron or a formula sheet. It also helped Mia and the instructor develop a plan to address any questions Mia might have while taking the exam at the DRC. Mia credited this instructor as the person who taught her how to better self-advocate in an undergraduate STEM course.

The experience Mia described taught her to ask her future STEM instructors questions about the exam logistics. She found this practice to be helpful, because she was better prepared to take her exam at the DRC. She also reported that it helped her instructors remember she was taking the exam away from the class, without access to announcements or resources they might share with the class extemporaneously on exam day. Many STEM instructors supported the self-advocacy of our participants in their courses. Yet this was not always the case. The next section describes how STEM instructors hindered self-advocacy.

STEM Instructors as a Barrier. Participants shared experiences when their STEM instructors either inadvertently or blatantly discouraged accommodation use in their courses. Several participants perceived self-advocacy to be more challenging to enact in their STEM courses because of their STEM instructors. Eli, a student with an SLD in reading, reported that his English instructors know more about dyslexia than his STEM instructors. He explained,

English instructors realize ... the processing speed for people with dyslexia is just slower. So everything just takes more time. It's not just reading and writing that is harder. Getting through everything just takes longer ... I feel like the English instruc- tors are more accustomed to having to deal with accommodations so they just know more about it. They know more than the STEM instructors.

Eli shared that he feels like he has to explain more to his STEM instructors than his English instructors, and this requires more self-advocacy. Aaron echoed this sentiment, "STEM instructors are stereotypically colder ... you have to do more advocacy, depending on the teacher." Although many of our participants view their STEM instructors as less likely to provide accommodations willingly than instructors in other disciplines, one participant disagreed. Kendra felt that her STEM instructors were "logical and very empirical," so they would understand that the symptoms of ADHD warrant use of accommodations, as noted in our previous paper (Pfeifer et al., 2020). Our participants also shared specific examples of how their STEM instructors hindered their self-advocacy. We describe how STEM instructors likely inadvertently hindered self-advocacy in the next section.

STEM Instructors Inadvertently Hinder Self-Advocacy. Our participants described specific incidences when their STEM instructors inadvertently discouraged their self-advocacy. We briefly describe these instances here. We saw that STEM instructors can unintentionally hinder self-advocacy in their choice of language when interacting with students. Kendra shared,

My instructor was like, "Ha, you're so crazy, I'm so happy you're not one of those people on medication and stuff." ... When your instructors say stuff like that, you just have to know that you have gone through a pretty rigorous process of getting evaluated for ADHD and just be confident in what you have, but also in yourself.

Kendra explained that she had an amicable relationship with this STEM instructor up to this point, but when her instructor implied that you must be "crazy" if you take medication, she felt less inclined to talk with instructors in the future about her disability and accommodations. For Kendra and other participants, instances like this could be considered examples of disability microaggressions, although none of our participants used the term "microaggression" to describe these occurrences (Keller and Galgay, 2010).

Our participants also explained that the comments instructors make about the amount of time students should be spending on an exam hindered their self-advocacy. Jake described that he decided not to use extended time on exams in an engineering class, because "we were taught to go through problems fast and efficient and if you didn't know them you wouldn't figure them out. So, I didn't use accommodations." It is likely that Jake's engineering instructor did not want to directly discourage Jake from using extended time for his exams when he said students should go through problems quickly. Yet Jake interpreted this language to mean that he should not use his extended-time accommodation.

Another participant, Aaron, shared that he was in a similar situation in which his STEM instructor would make general prescriptive statements about how much time students should take to answer questions on the exam, "I had one instructor that was saying I should know how to do the problems before I come in 
to do the exam ... the instructor said that if you know how to do the problems then it shouldn't take you that much time to complete the exam." Aaron found it very frustrating when instructors tell the entire class how much time a single problem should take to complete. It is possible that the instructors in these cases described by Jake and Aaron were prescribing time guidelines for the perceived benefit of their students. However, it is not clear if these instructors were considering the experiences of all their students, including students who use extended-time accommodations, when they made these announcements to the class.

We found other factors of the classroom environment that hindered self-advocacy. For instance, instructors may inadvertently hinder self-advocacy by adopting "anti-technology" policies in the classroom. Eli, a student who qualifies to record lectures on his laptop in class, shared that he did not want to "push the boundary" with his STEM instructor. He knows that technically he could record lectures, but he does not want to: "It's felt kind of awkward being the only one in the room with my laptop up, even though it's probably something I should be doing." Eli explained that he feels he loses his confidentiality when he is the only student using a laptop in the class.

Besides these specific examples of how STEM instructors inadvertently hindered self-advocacy, our participants also described how STEM instructors unfamiliar with their own responsibilities as an instructor in the accommodation process hindered students' self-advocacy. Cassie reported, "My math instructor my freshman year, he wasn't being responsive to my accommodation requests. I think he was ... new to teaching, so I think he was just confused about what to do." Many of our participants had experiences similar to Cassie with STEM instructors who lacked knowledge of the role of an instructor in the accommodation process. Oftentimes, these instances were difficult for our participants to navigate, because it was early in their college careers when they were still learning how the accommodation process works in college. Lack of knowledge regarding the accommodation process from both the STEM instructor and the participant made self-advocacy more challenging.

We found that several participants did not initiate communication with their STEM instructors for the purpose of self-advocacy because they did not want to burden the instructor. Henry said that, when he is in a large-enrollment STEM course, he feels less likely to communicate with his instructor about accommodation issues, because he realizes the instructor is responding to the needs of many students. He stated,

I feel like if I have an accommodation issue, I just have to deal with it myself because ... everyone has a lot of issues and everyone is emailing the professor about something. Sometimes I feel less compelled to speak up for myself because of it.

Henry explained that he considers the instructor's time before he communicates about an accommodation issue. Other participants, like Dana, expressed a similar sentiment. She stated that she does not make accommodation requests, in part because she does not want to create extra work for her STEM instructor. Dana stated throughout her interview that she sees her instructors are very busy and not able to prioritize teaching due to demanding research agendas. Her perception was that her instructors do not have time to attend to her accommodation needs, because they prioritize conducting research over teaching. Many of our participants discussed how STEM instructors are inadvertently discouraging them from using accommodations or how their perceptions of their STEM instructors hinder their self-advocacy. We found some rare instances of STEM instructors blatantly discouraging the use of accommodations in their courses, which hindered our participants' self-advocacy.

STEM Instructors Discourage Use of Accommodations. Our participants shared that some STEM instructors discouraged accommodation use in their courses, which hindered our participants' self-advocacy. One example of how STEM instructors discouraged use of accommodations was by violating the privacy of our participants. This often occurred when a STEM instructor would reveal to the entire class that a participant was the student needing a note-taking accommodation in the course or by discussing extended-time accommodations with a participant in front of peers. When STEM instructors violated the privacy of our participants, it made our participants wary of requesting accommodations in future courses, because they worried that the next instructor would also disclose their disability status to their peers.

Additionally, STEM instructors blatantly discouraged accommodation use by telling our participants their accommodations would be difficult to implement in their STEM courses. One example of a STEM instructor blatantly discouraging use of accommodations came from Henry. Henry, a first-year student, arranged to meet with his chemistry instructor to ask if he could use accommodations in the lab section of the course. We asked Henry if he planned to formally request accommodations for the lab, he replied, "None of my accommodations will ... my chemistry instructor said they wouldn't work out very well." Here, Henry was practicing self-advocacy. He wanted to learn about the STEM learning context from his chemistry instructor to determine how he could use his extra time accommodation for the in-class quizzes at the beginning of lab each week. The conversation with his chemistry instructor directly discouraged Henry from making a formal accommodation request.

One of the most extreme examples of how a STEM instructor blatantly discouraged accommodation use, and thus hindered self-advocacy, was reported by Mia. Mia explained that, at the college she had transferred from, her genetics instructor "really pressured me to take the exam in class, without my extended-time accommodation ... and that resulted in a really, really low score." Mia reported that her genetics instructor did this because he did not consider dyslexia to be a "real disability." Fortunately, Mia communicated with her DRC coordinator and reported the incident to the DRC. The DRC reminded the STEM instructor that Mia is legally entitled to these accommodations. With the help of the DRC, she was able to access accommodations for subsequent exams in the course.

Finally, our participants reported that their STEM instructors can be negligent of their responsibilities as instructors in the accommodation process. For example, Opal shared that she encountered difficulty using her accommodations, because one of her STEM instructors still had not approved her accommodation request in the online accommodation system for online quizzes. When STEM instructors failed to respond to accommodation 
requests and follow-up emails from our participants in a timely manner, it left many participants wondering what the lack of response meant. Because we interviewed only students and not instructors, we were unable to determine whether instructor negligence was an example of inadvertent or blatant discouragement of accommodation use in their courses. Regardless of intent, it hindered Opal's self-advocacy. This type of negligence was reported by other participants, as well.

\section{Norms and Values of STEM as a Discipline}

In this section, we present data showing how our participants' perceptions of the norms and values of STEM as a discipline influenced their self-advocacy. We found these data often connected to internal factors influencing self-advocacy. We first explain how some participants perceived self-advocacy to be a way to show their STEM instructors that they are good students. They viewed STEM as a discipline that values students who work hard to succeed, and this perception supported their self-advocacy. We then explain how other participants perceived their disability or disabilities to be negatively viewed in the context of STEM as a discipline, and how this perception hindered their self-advocacy.

I Am a Good Student If I Self-Advocate. Some participants see self-advocacy as a way to demonstrate to their STEM instructors that they are good students who are engaged in the learning process. One example of this perception comes from Claudia. She felt that talking to her instructors about ADHD and accommodation use was a way to show them she is invested in her own learning as a student. Claudia shared that she engages in self-advocacy behaviors because "it shows that I'm an active student ... I seem less like a bad student." Other participants expounded on this perception by explaining that they want to practice self-advocacy with their instructors, because they think their instructors will approve of their efforts to succeed in a STEM course. Carter explained that he is comfortable self-advocating with his STEM instructors, because:

I feel like at the end of the day, especially if my STEM instructors know that I'm receiving these accommodations ... and I'm doing well, they will see that I am overcoming [adversity], like outside things that I can't control. I feel like ... they'll see you. Like this kid really knows what they're doing. They're really trying their hardest.

Carter continued to say that he perceives self-advocacy to be positively viewed by his STEM instructors, because it means he is trying to help himself succeed in their courses. Not all of our participants articulated this view of self-advocacy. Many of our participants shared that their perceptions of the norms and values of STEM as a discipline hindered their self-advocacy, because they felt like people with ADHD/SLD were viewed negatively within the discipline, or that they were not as valuable as individuals, because they differed from the typical student.

Perceptions of Individuals with ADHD/SLD in STEM. Our participants described their perceptions of STEM courses as students with ADHD/SLD and how their perceptions of what personal characteristics are valued in a STEM course functioned as a barrier to their self-advocacy. Dana described feeling like she has to defend her decision to pursue a STEM major as a student with ADHD. "When you have ADHD in STEM it's hard, people kind of look at you like why are you even doing it? Like it's just hard for you. You might as well find something easier." Dana's quote illustrated her perception that other people in STEM do not think she can succeed in STEM as a student with ADHD. Another participant, Cassie, elaborated that she felt like she is an outsider to STEM, because her brain works differently than her peers.

With the atmosphere of STEM courses and the STEM field in general, being like [able to] think on your feet, be quick. Have the answer pop out of your head when you look at a graph. In my head, if I can't do that, I'm not as good as these other people.

Cassie described that she perceives the ability to quickly answer a question to be highly valued in her STEM courses. She felt that she is not equal to her peers if she takes a longer amount of time to produce the same correct answer.

Participants also explained how they perceive others in their STEM courses to think about people with disabilities. For example, many participants with ADHD stated that their instructors and peers do not think it is fair for them to use accommodations, because ADHD is not considered to be a "real disability." This perception made communicating for the purpose of self-advocacy challenging. For instance, Isabel stated that her peers do not think it is fair for her to use accommodations, because "it's just ADHD." Kendra revealed to us that she prefers to tell people she "just has a learning disability," instead of sharing that she is diagnosed with ADHD, because she perceives others to view ADHD negatively.

Participants with a specific learning disability in reading described how the stigma of dyslexia is manifested in STEM courses. Megan shared that people think having dyslexia means you are just bad at spelling, but they do not realize there can be more to having dyslexia. She further explained that this reductionist view of dyslexia makes her less likely to communicate with others about her disability, because "it's frustrating when I would say something about having dyslexia and people don't understand at all." Another participant with a specific learning disability in reading, Mia, shared that she perceives dyslexia to be tied to stigma, but that this stigma is not isolated to STEM courses exclusively. Mia reported, "People with dyslexia are seen as less intelligent than the average person just because their brain processes the same information in a different way." Several of our participants reported that they felt different from their peers in a STEM course and not well understood by those around them. These feelings made communicating for the purpose of self-advocacy intimidating and difficult.

\section{The Nature of STEM Courses and Its Influence on Self-Advocacy}

In an effort to further contextualize the factors that influenced the self-advocacy of our participants in undergraduate STEM courses, we asked our participants, "How does self-advocating in a STEM course compare to self-advocating in a different type of course?" Rarely did participants report that there was no difference between self-advocating in an undergraduate STEM course versus a non-STEM course. Participants explained 
several aspects of undergraduate STEM courses that pose challenges to them in terms of their self-advocacy. We include these data as a separate section to describe the unique self-advocacy experiences students with ADHD/SLD encounter in undergraduate STEM courses. We note that these data overlap with many of the factors influencing self-advocacy.

Several participants shared that the technical nature of STEM content will require them to use their accommodations in order to be successful in the course. Judd shared his perception of practicing self-advocacy in an undergraduate STEM course as a learner with a disability:

I think that STEM is probably the hardest to adapt to as having a learning disability ... [STEM] is just rigorous, requires a lot of time, a lot of critical thinking, a lot of stuff that, on your psych eval, you were told you were missing. So it's kind of like, since you're missing this, you're probably not going to make it in STEM.

Judd went on to explain that he is determined to succeed in his STEM courses, even if he views others as thinking he is not likely to graduate as a STEM major because of his disability.

For many participants, the main accommodations they use are exam accommodations (e.g., extended time in a less distracting environment). Because STEM courses tend to use exams as the major form of student assessment, several participants explained they are more likely to use accommodations in STEM compared with non-STEM courses. Oakley stated, "Math and science, it's a lot of practicing different types of problems in different settings, different scenarios and I feel like in nonSTEM courses, it's more discussion based and more writing papers." Opal reiterated this point. She further explained how the detail-oriented nature of STEM content requires her to use extra time on her exams because of her disability. She stated,

With math and science, you have so many steps in between where you have to go back and check the equation, and then check that you gathered the right numbers from the table, and then check to see that you have the right states of matter, and then check to see if you're copying the long decimal from the equation above the same, and the equation below, and you're typing it right into your calculator ... and you need to make sure again that you're typing it right. I don't find the need to double check myself so often with non-STEM courses, whereas in STEM, I need that extra time. In a non-STEM course ... I usually finish on time. With my STEM courses, I realize holy cow, I need these 45 extra minutes [on my exam].

Finally, our participants explained that the many learning contexts that they encounter as STEM majors make self-advocacy challenging. For instance, many participants shared that they did not realize that they could request accommodations in a lab section of a STEM course. A few participants stated they needed accommodations for in-lab quizzes. Most of our participants explained that they only needed accommodations for summative assessments in STEM lab sections, such as for lab practicals. When participants did use accommodations for lab practicals, they sometimes found that their confidentiality was compromised, because the rest of the class could see that they continued working after the rest of the class was asked to stop. One example of this comes from Carter, who used his extended-time accommodation for his anatomy lab practical.
I remember when the lab practical was over in my anatomy class, [the teaching assistants] were like, "Cool everybody go," and people looked at me like, "Hey how come he's not leaving?"

Carter continued to say, "People kinda look at you, they set you away from the pack if you will, and they think of it as weakness, or like you're stupid, but it's okay." Carter's positive self-advocacy beliefs appeared to help him practice self-advocacy in this situation. The totality of our data regarding self-advocacy experiences in undergraduate STEM courses allowed us to develop a model of factors influencing the self-advocacy of our participants.

\section{A Model of Factors Influencing the Self-Advocacy of our Participants}

Based on our participants' experiences, we generated a model of the factors that influenced their self-advocacy behaviors within undergraduate STEM courses (Figure 2). The purpose of this model is to define the factors that influence self-advocacy in an effort to begin characterizing mechanisms that affect self-advocacy behaviors in undergraduate STEM courses. We found that the internal and external factors discussed by our participants could either support or hinder self-advocacy. Determining whether a factor functioned as a support or barrier depended upon the participant and that participant's unique experience. The factors also frequently interacted. For instance, our participants discussed how they gained self-advocacy knowledge (an internal factor) from their own previous experiences with the logistics of accommodations (an external factor) and from other individuals (another external factor). The internal factors, self-advocacy beliefs and identity, were affected by external factors for some of our participants. We could also see in our data that the internal factors, self-advocacy beliefs and identity of a participant, influenced that participant's perceptions of external factors. For example, participants who tended to see their own disability in a negative manner tended to perceive their peers as a barrier to self-advocacy, because they tended to assume that a majority of their peers would view accommodation use negatively. Internal and external factors, as well as the interactions between factors, affected 1) a participant's sense of comfort and security as a student with ADHD/SLD and 2) a participant's perception that accommodation use is accepted within a particular context. Both a sense of comfort and a perception that accommodation use is accepted in a STEM course promoted self-advocacy behaviors. Conversely, when participants did not feel comfortable or secure as a student with $\mathrm{ADHD} / \mathrm{SLD}$, or when they did not perceive accommodation use to be accepted in an undergraduate STEM course, self-advocacy behaviors were diminished. Our model of the factors influencing self-advocacy suggests directions for future research and provides implications for teaching undergraduate STEM courses.

\section{DISCUSSION}

In our study, we used an in-depth qualitative approach to characterize the factors that supported or hindered our participants' self-advocacy behaviors in undergraduate STEM courses. Our model illustrates that internal and external factors work in concert to influence a sense of comfort and security as a student 


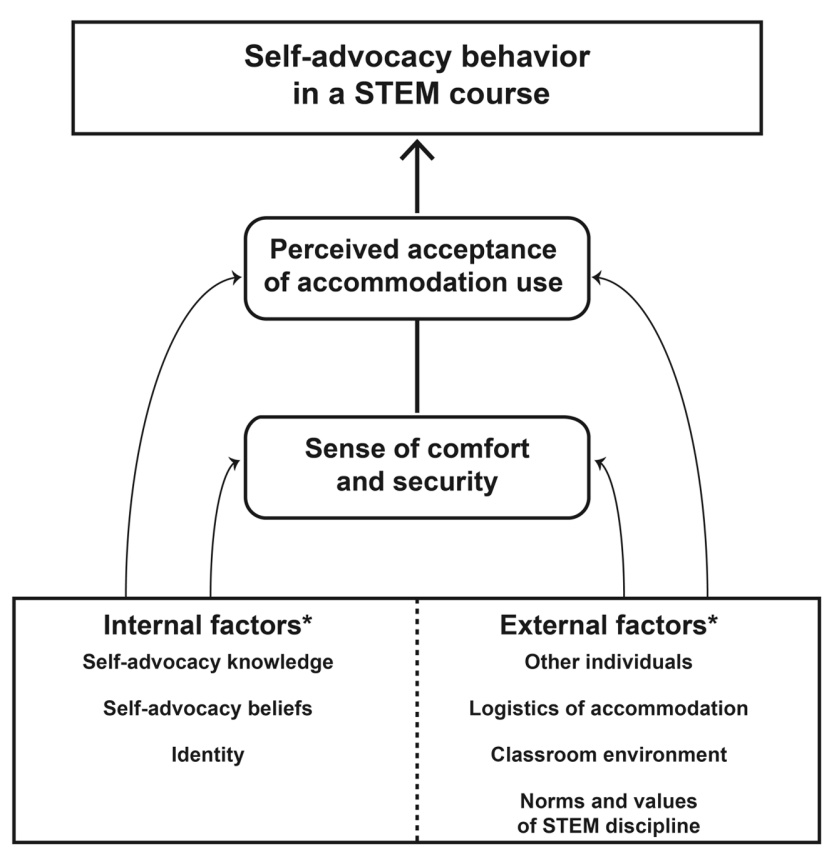

*Function as a support or barrier, depending upon individual and their contexts

FIGURE 2. Our emergent model describing how factors influence the self-advocacy of our participants in the context of undergraduate STEM courses. Square-edged boxes represent findings from our data, while round-edged boxes represent components that we propose influence self-advocacy behaviors in a STEM course. Internal factors are aspects of self-advocacy within our participants. External factors are aspects that influence self-advocacy outside the participants. Internal and external factors often interact (dashed line). Factors function as a support or as a barrier (arched lines), depending upon the individual participant and that participant's experiences. The lines are intended to be multidirectional. Factors contribute to or diminish a sense of comfort and security and inform our participants' perceptions that accommodation use is accepted within a STEM course. Sense of comfort and security and a perceived acceptance of accommodation use function together (straight, bolded arrow) to support self-advocacy behaviors in STEM courses.

with ADHD/SLD and the perceived acceptance of accommodation use in a STEM course, which in turn affects self-advocacy behaviors. We situate the results of our study within the literature while discussing implications of our results for research and teaching.

\section{Implications for Research}

The major contribution of our research is a deeper understanding of the complexity of practicing self-advocacy in undergraduate STEM courses. Our study suggests that the social model of disability does not fully capture the intricacy of this experience. At the surface level, the social model of disability argues that an individual with an impairment can address the hardship of societal expectations, and thus disability, through self-advocacy (Goodley, 1997). However, in our view, the social model of disability does not fully account for the effect of the context, which makes an individual more or less likely to engage in self-advocacy in the first place. In this study, we found participants to vary in self-advocacy, although they were all experiencing a similar societal context-undergraduate STEM courses. The social model of disability tends to overlook internal factors, such as identity, that can influence the self-advocacy of our participants. The intersectional nature of identity influences the experiences of a student in the context of undergraduate STEM (e.g., Ireland et al., 2018) and affects many educational constructs such as sense of belonging in STEM (e.g., Rodriguez and Blaney, 2020). Future self-advocacy research may be better served by other theoretical frameworks, such as Tinto's model of student retention, that more robustly attend to the role of identity, and other internal factors, in self-advocacy (Tinto, 1993).

Our results show that factors must be considered within a context to determine whether they are functioning as a support or barrier to self-advocacy. For example, participants described their STEM instructors as a support to their self-advocacy when the STEM instructors follow up with them about their accommodations. However, the context of this conversation is important. If this conversation occurs in front of peers, it can be perceived as violating privacy, and therefore acts as a barrier to self-advocacy. In some ways, finding that context influences self-advocacy is not surprising, because as our study and others demonstrate, the experience of disability is highly individualized (e.g., Mullins and Preyde, 2013). Nonetheless, viewing context as a contributor to the formation of a support or a barrier is valuable. The model generated by our analysis can be used to inform future research in undergraduate STEM and to test what supports and barriers exist in other educational settings. Our model also establishes the importance of studying self-advocacy and accommodation use in a highly contextualized manner, such as within the STEM discipline, to fully characterize the underlying processes affecting self-advocacy.

Some of the factors identified by our analysis are already known to influence students with disabilities in college. For instance, we identified that students who were still developing their self-advocacy knowledge struggled to engage in self-advocacy behaviors within their STEM courses (Pfeifer et al., 2020). Two studies of college students with learning disabilities found participants possessed varying levels of knowledge in relation to their own learning disabilities, which influenced accommodation use and self-advocacy (Cawthon and Cole, 2010, Cole and Cawthon, 2015). Another study found that other individuals, such as educators and family members, supported the development of self-advocacy in $\mathrm{K}-12$ settings (Daly-Cano et al., 2015). Our results demonstrated that the support of educators and family does not end in high school. Many of our participants reported that the information and advice provided by their STEM instructors and families continued to support their self-advocacy in college.

We identified additional factors besides self-advocacy knowledge and other individuals that influenced our participants' self-advocacy. One of our participants, Dana, described her DRC coordinator as a barrier to her self-advocacy, because Dana perceived the accommodation process to be prescriptive (Supplemental File 3). Dana described feeling forced to choose her accommodations from a list based on her diagnosis, not from her own experiences and needs as an individual. It has been suggested that the notion that accommodations are prescriptive, or a "menu of services" that can be "selected on a case-bycase basis," contributes to student perceptions of ineffective 
accommodations (Richard, 1995; Kurth and Mellard, 2006). This result exemplifies how self-advocacy can be influenced by both other individuals and the systems embedded within higher education. It also highlights the importance of conducting self-advocacy research in a manner that preserves the accommodation context of a university or college within the analysis, because this context matters in the experience of the participant. Finally, our results suggest that STEM majors with ADHD/ SLD may be more likely to use accommodations in their STEM courses compared with other disciplines; however, more research is needed to determine whether this result is found in other settings.

\section{Implications for Teaching}

In our study, the classroom environment influenced the self-advocacy of our participants. Because classroom environments, in part, are controlled by STEM instructors, we considered the actions of STEM instructors to be related to the classroom environment. Some participants shared examples of how STEM instructors supported their self-advocacy. For example, a calculus instructor supported the self-advocacy of one of our participants, Jake, by helping him realize he may be experiencing issues completing his exams due to ADHD and connected him with the DRC to establish accommodations. However, we found that many participants perceived their STEM instructors as generating barriers to self-advocacy. We summarize these perceived barriers and explain how they hinder self-advocacy. We also provide supports that can overcome barriers to self-advocacy in undergraduate STEM courses (Table 3).

Our participants reported that they perceived some of their STEM instructors to be uninformed about their experiences and that some STEM instructors use language or enact classroom policies that discouraged their use of accommodations. Examples of this type of language included STEM instructors joking about "being dyslexic" or "being ADHD" or implying that a student must be "crazy" if they take medication. We also found that, when STEM instructors made general prescriptive announcements to the class about the amount of time a task "should" take to complete or adopted "anti-technology" policies in their courses, the self-advocacy of our participants was hindered. Participants reported examples of hurtful or dismissive language used by STEM instructors that was reminiscent of negatively phrased instructor talk found to dismantle the student-instructor relationship, disestablish the classroom culture, compromise pedagogical choices, and share personal judgment (Harrison et al., 2019). Such language and certain classroom policies represent cues from the instructor that diminish students' sense of comfort and security and inform their perceptions that accommodation use is not fully accepted in a STEM course.

Within our study, we found that some participants perceived themselves to be excluded from their STEM courses. For some participants, their feelings of exclusion from their STEM courses could be amplified by the interaction of their disability identity with other facets of identity, such as gender and race. These findings are related to issues of inclusivity within undergraduate STEM courses. We encourage STEM instructors to consider disability as another aspect of student diversity (Ben-Moshe and Magaña, 2014; Vaccaro et al., 2015). Considering disability in this manner can help instructors enhance inclusivity within their own courses by developing their own self-awareness and fostering empathy for students with ADHD/SLD, students with other types of disabilities, and students representing other facets of diversity (Dewsbury and Brame, 2019).

Seeking opportunities to learn more about students with $\mathrm{ADHD} / \mathrm{SLD}$ and other disabilities is likely to enhance the inclusiveness of a STEM course. STEM instructors can demonstrate to students with ADHD/SLD that they are willing to learn about their unique experiences by inviting students to discuss disability or accommodation issues with them in a private meeting at the start of a course. Many of our participants shared that they do not feel comfortable talking to their STEM instructors during open-door office hours, because they worry about losing confidentiality. We emphasize that STEM instructors should invite their students, but not insist they meet with them, because it is the student's right to choose to engage in follow-up communication with a STEM instructor. In our own teaching experience, making a short announcement at the start of the course stating that we fully support the use of accommodations in our course has increased the number of students who use their accommodations. We hypothesize that, when STEM instructors make these types of announcements at the start of a course, it demonstrates to students with ADHD/SLD that these instructors will support their self-advocacy. It may help students feel more comfortable to engage in communication for the purpose of self-advocacy and may clarify to students that classroom practices or policies are not in place to discourage accommodation use.

We found that participants perceived STEM instructors to hinder their self-advocacy when the instructors lacked knowledge or neglected their own role as an instructor in the accommodation process. An instructor's lack of awareness about the accommodation process made it challenging to practice self-advocacy, because the student was often still developing self-advocacy knowledge. One study of college faculty indicated faculty have general and limited knowledge about laws related to disability in higher education that drive the accommodation process in postsecondary settings (Villarreal, 2002). Two recent studies suggest that STEM instructors want to support student use of accommodations, but they feel unprepared to do so, in part, because they feel they lack the necessary knowledge (Love et al., 2014; Gokool-Baurhoo and Asghar, 2019). In one interview study conducted with five STEM faculty, participants reported that they gained their knowledge of accommodations and disabilities through experience "on the job," and one participant had "no formal educational opportunities working with students with disabilities" (Love et al., 2014, p. 33). This lack of preparation is troubling, given the major influence STEM instructors had on the self-advocacy of our participants.

Our data and other studies show that self-advocacy involves negotiation of power structures inherent to instructor-student relationships (Trammell, 2009; Charlton, 2010). For example, Henry attempted to negotiate against a power differential when he met with his chemistry instructor to ask about using his extended-time accommodation on the quizzes in the lab section of the course. The instructor implied to Henry that his accommodations could be difficult to implement, so Henry did not request them, because he did not want to complicate his relationship with the instructor. In this instance, Henry may have benefited from informing his DRC coordinator about the situation; his DRC coordinator could have explained to the instructor 
TABLE 3. Perceived self-advocacy barriers generated by STEM instructors and recommended practices to support self-advocacy in STEM courses

Barrier perceived by student
Instructor is uninformed about the
experiences of students with
ADHD/SLD in STEM course.
Instructor is uninformed about the
instructor's role in the accommo-
dation process.
Instructor fails to respond to
accommodation requests or emails
about issues in a timely manner.
Instructor discusses accommodation
or accommodation issues openly
in front of peers.

Instructor tells student that accommodations would be "difficult" to implement in a lab or other STEM contexts.

Instructor actively discourages student from using exam accommodations.

Instructors use dismissive or hurtful language. For example, making jokes about "being ADHD" or "being dyslexic" in front of the class.

Instructor makes statements prescribing the amount of time it "should" take a student to complete an exam question or the entire exam.

Instructor adopts "anti-technology" policies in the classroom.

Instructor fails to develop a plan to proctor in-class quizzes so that students using extended-time accommodations can use their accommodations in a confidential manner.

Instructor fails to provide equal access Both to information on exam day to students taking the exam at the DRC.

Both

Both

Both

Both

Both

Both perceived acceptance of accommodation use and sense of comfort and security

Perceived acceptance of accommodation use

Perceived acceptance of accommodation use

Sense of comfort and security
Supports to self-advocacy that can overcome barriers

Consider disability a facet of student diversity. Seek opportunities to learn about student experiences.

Visit your campus DRC website, seek professional development opportunities offered by the DRC, and communicate with colleagues in your department to learn what is expected of instructors.

Communicate to students how long you typically take to respond to accommodation requests or emails. If you have a question about the accommodation requested, communicate with the student and DRC coordinator as soon as possible.

Take your cue from the students. If they initiate conversations with you in front of their peers, it is likely they feel comfortable talking about accommodations in that situation. If they do not initiate conversations with you in front of their peers, communicate with students via email or offer to schedule a meeting to talk in-person about accommodations or issues. In our study, students reported they did not feel comfortable talking about accommodations with their instructors if they thought a peer could hear them talking with an instructor.

Explain to students that you are willing to help them access their accommodations in a lab, even if it may be difficult for you to figure out how to do this at first. Discuss best options to implement an accommodation with the student and the DRC coordinator. Communicate with the DRC coordinator to ask questions you have about the accommodation. The DRC can often help find a workable solution for you and the student.

Students are legally entitled to use their accommodations. If you feel a requested accommodation fundamentally alters the nature of the course, you can communicate this to the DRC and work with the DRC to find a solution.

Consider the experiences of all students in your classroom before making these statements. Remember that using disability terms when they do not apply can be a barrier to students.

Avoid making general prescriptive statements about the time a student "should take" to complete an exam or a question on the exam. If you do make these types of statements, qualify them. Explain that some students may take longer or shorter time, and that is also acceptable.

Explicitly state to the class and in your syllabus that technology for accommodation purposes is an exception to this rule and that you fully support the use of accommodations in your course.

Consider how students using extra time will complete the quiz without missing class instruction. Communicate options to students to see what they may prefer. Some possible solutions include:

1 . Proctoring the quiz online before class.

2. Proctoring the quiz at the end of class, so students can either take the quiz at the DRC or stay after class to complete the quiz with extra time.

Consider the exam day experiences of students testing at the DRC. Ask yourself these questions to develop policies that ensure equal access to information:

1. Did I include all necessary information (e.g., formula sheet, periodic table, etc.) to take the test?

2. Do I make announcements to the class that students testing at the DRC would not have access to?

3. Do I answer student questions about the exam when the test is in class, but not at the DRC? How can I ensure both groups of students can ask questions? 
that Henry was entitled to use accommodations on lab quizzes. Because we did not interview STEM instructors, we can only speculate whether the chemistry instructor in this case was fully aware of the power the instructor holds in the accommodation process. While the process to obtain accommodations may differ depending upon the university or college, in general, the instructor must at least acknowledge the accommodation requested for each student in a course. If the instructor feels that the accommodation "fundamentally alters" the nature of a course, it is within the instructor's rights to communicate with the DRC to explore other accommodation options. If the chemistry instructor felt the extended-time accommodation on lab quizzes accommodation would be difficult to implement, it would have been better to discuss the issue with Henry and his DRC coordinator to find a workable solution for all parties involved. It is important instructors are aware of the power they hold in the classroom and within the accommodation process. Being more aware of this power may help STEM instructors be better supporters of self-advocacy.

In our study, our participants reported that some STEM instructors excelled as supporters of self-advocacy, while other STEM instructors did not. It is clear from our study that concerted efforts are needed to better prepare STEM instructors to be effective supporters of self-advocacy and to create classroom environments conducive to self-advocacy. It is likely that enhancing student self-advocacy by itself is necessary, but not sufficient, to promote the retention of students with ADHD/SLD and other disabilities in STEM. We are more likely to retain students with disabilities in STEM by simultaneously enhancing student self-advocacy and STEM instructor knowledge.

\section{Limitations}

Data were collected from 25 individuals at a single university who were currently registered to receive services from a DRC for ADHD/SLD. A majority of our participants were white, life sciences majors, and reported having only ADHD. We examined the self-advocacy experiences of STEM majors broadly, as opposed to life science majors exclusively. Because our participants were already registered and willing to participate in our study, many of our participants likely represent individuals with developing or well-developed self-advocacy. Our data do not encompass the perspectives of individuals with ADHD/SLD who have never registered with their campus DRC, and this difference in experience may or may not include the factors influencing self-advocacy that were identified in this study. Additionally, our participants currently requested their accommodations using an online accommodation system. This practice eliminates the requirement of students taking a physical copy of their accommodation letters to their instructors, as occurs at some universities and colleges. We expect the details of how students access their accommodations will influence their self-advocacy and their perceptions of what supports and hinders self-advocacy in undergraduate STEM courses. Future research is needed to understand whether and how the factors identified in our study apply to other students with ADHD/SLD in different contexts.

\section{CONCLUSION}

Our study is part of an emergent body of research regarding the experiences of students with disabilities in undergraduate
STEM contexts (Braun et al., 2017; Majocha et al., 2018; Gin et al., 2020; McCall et al., 2020; Pfeifer et al., 2020). Across these studies, a pattern appears. Students with disabilities report perceptions of exclusion from STEM. We encourage all STEM instructors to consider disability as a feature of student diversity. Our aim in disseminating the factors that influenced the self-advocacy of our participants is to bring attention to the ways STEM instructors can support or hinder the self-advocacy of their students. We call on STEM instructors to deeply consider the language and practices they use within their own courses and to take action to support the self-advocacy of their students. Supporting the self-advocacy of students with ADHD/ SLD is likely to encourage accommodation use in STEM courses, and this, in turn, will promote retention of students with ADHD/ SLD and other disabilities in undergraduate STEM majors.

\section{ACKNOWLEDGMENTS}

We are grateful to our participants and members of the University of Georgia's (UGA) Disability Resource Center (DRC) speakers' bureau. We acknowledge McKenna Hendrickson for her contributions to preliminary analysis for this project. We also thank our past and present partners, especially Patricia Roth Marshall, Sam Adair, and Erin Benson at the UGA DRC. We thank the Biology Education Research Group at UGA for their ongoing support and for their feedback on an early version of this article. This material is based upon work supported by the NSF Graduate Research Fellowship Program under Grant Number 1842396 (in support of M.A.P.), and by the NSF under the Peach State Louis Stokes Alliance for Minority Participation grant number 1619689 (in support of J.J.C.). Any opinions, findings, and conclusions or recommendations expressed in this material are those of the author(s) and do not necessarily reflect the views of the NSF. This research was supported in part by funds from the Division of Student Affairs at UGA (to J.D.S. and M.A.P.).

\section{REFERENCES}

American Psychiatric Association. (2013). Diagnostic and statistical manual for mental disorders (5th ed.). Arlington, VA

Ben-Moshe, L., \& Magaña, S. (2014). An introduction to race, gender, and disability: Intersectionality, disability studies, and families of color. Women, Gender, and Families of Color, 2(2), 105-114

Berghs, M., Atkin, K., Graham, H., Hatton, C., \& Thomas, C. (2016). Implications for public health research of models and theories of disability: A scoping study and evidence synthesis. Public Health Research, 4(8), 1-166. doi: 10.3310/phr04080

Braun, D. C., Gormally, C., \& Clark, M. D. (2017). The Deaf Mentoring Survey: A community cultural wealth framework for measuring mentoring effectiveness with underrepresented students. CBE-Life Sciences Education, 16(1), ar10. doi: 10.1187/cbe.15-07-0155

Budd, J., Fichten, C. S., Jorgensen, M., Havel, A., \& Flanagan, T. (2016). Postsecondary students with specific learning disabilities and with attention deficit hyperactivity disorder should not be considered as a unified group for research or practice. Journal of Education and Training Studies, 4(4), 206-216.

Cawthon, S. W., \& Cole, E. V. (2010). Postsecondary students who have a learning disability: Student perspectives on accommodations access and obstacles. Journal of Postsecondary Education and disability, 23(2), $112-$ 128.

Charlton, J. (2010). The dimensions of disability oppression. Disability Studies Reader, 3, 147-159.

Charmaz, K. (2006). Constructing grounded theory: A practical guide through qualitative analysis. London: Sage. 
Cole, E. V., \& Cawthon, S. W. (2015). Self-disclosure decisions of university students with learning disabilities. Journal of Postsecondary Education and Disability, 28, 163-179. Retrieved December 3, 2019, from https:// eric.ed.gov/?id=EJ1074663

Daly-Cano, M., Vaccaro, A., \& Newman, B. (2015). College student narratives about learning and using self-advocacy skills. Journal of Postsecondary Education and Disability, 28(2), 213-227.

Dewsbury, B., \& Brame, C. J. (2019). Inclusive teaching. CBE-Life Sciences Education, 18(2), fe2. doi: 10.1187/cbe.19-01-0021

Dunn, C., Rabren, K. S., Taylor, S. L., \& Dotson, C. K. (2012). Assisting students with high-incidence disabilities to pursue careers in science, technology, engineering, and mathematics. Intervention in School and Clinic, 48(1), 47-54. doi: 10.1177/1053451212443151

Dunn, D. S., \& Andrews, E. E. (2015). Person-first and identity-first language: Developing psychologists' cultural competence using disability language. American Psychologist, 70(3), 255.

DuPaul, G. J., Gormley, M. J., \& Laracy, S. D. (2013). Comorbidity of LD and ADHD: Implications of DSM-5 for assessment and treatment. Journal of Learning Disabilities, 46(1), 43-51.

Eckes, S. E., \& Ochoa, T. A. (2005). Students with disabilities: Transitioning from high school to higher education. American Secondary Education, $33(3), 6-20$

Fram, S. M. (2013). The constant comparative analysis method outside of grounded theory. Qualitative Report, 18(1), 1-25.

Getzel, E. E., \& Thoma, C. A. (2008). Experiences of college students with disabilities and the importance of self-determination in higher education settings. Career Development for Exceptional Individuals, 31(2), 77-84 doi: $10.1177 / 0885728808317658$

Gin, L. E., Guerrero, F. A., Cooper, K. M., \& Brownell, S. E. (2020). Is active learning accessible? Exploring the process of providing accommodations to students with disabilities. CBE-Life Sciences Education, 19(4), es12.

Gokool-Baurhoo, N., \& Asghar, A. (2019). "I can't tell you what the learning difficulty is": Barriers experienced by college science instructors in teaching and supporting students with learning disabilities. Teaching and Teacher Education, 79, 17-27.

Goodley, D. (1997). Locating self-advocacy in models of disability: Understanding disability in the support of self-advocates with learning difficulties. Disability \& Society, 12(3), 367-379.

Hadley, W. M. (2007). The necessity of academic accommodations for firstyear college students with learning disabilities. Journal of College Admission, 195, 9-13.

Haegele, J. A., \& Hodge, S. (2016). Disability discourse: Overview and critiques of the medical and social models. Quest, 68(2), 193-206. doi 10.1080/00336297.2016.1143849

Harbour, W. S., \& Greenberg, D. (2017). Campus climate and students with disabilities. Huntersville, North Carolina: National Center for College Students with Disabilities (NCCSD) Association on Higher Education and Disability (AHEAD)

Harrison, C. D., Nguyen, T. A., Seidel, S. B., Escobedo, A. M., Hartman, C., Lam, K., ... \& Tanner, K. D. (2019). Investigating instructor talk in novel contexts: Widespread use, unexpected categories, and an emergent sampling strategy. CBE-Life Sciences Education, 18(3), ar47. doi: 10.1187/cbe.18-10-0215

Hedrick, B., Dizen, M., Collins, K., Evans, J., \& Grayson, T. (2010). Perceptions of college students with and without disabilities and effects of STEM and non-STEM enrollment on student engagement and institutional involvement. Journal of Postsecondary Education and Disability, 23(2), 129136.

Ireland, D. T., Freeman, K. E., Winston-Proctor, C. E., DeLaine, K. D., McDonald Lowe, S., \& Woodson, K. M. (2018). (Un)hidden figures: A synthesis of research examining the intersectional experiences of black women and girls in STEM education. Review of Research in Education, 42(1), $226-$ 254.

Isaacson, M. D. \& Michaels, M. (2015). Ambiguity in speaking chemistry and other STEM content: Educational implications. Journal of Science Education for Students with Disabilities, 18(1), 1-9.

Isaacson, M. D., Srinivasan, S., \& Lloyd, L. (2011). Ambiguity and inconsistencies in mathematics spoken in the classroom: The need for teacher training and rules for communication of mathematics. Journal of Science Education for Students with Disabilities, 15(1), 5.

Izzo, M., \& Lamb, M. (2002). Self-determination and career development Skills for successful transitions to postsecondary education and employment (A white paper for the Post-School Outcomes Network of the National Center on Secondary Education and Transition (NCSET) at the University of Hawaii at Manoa). Retrieved December 3, 2019, from www.ncset.hawaii.edu/Publications

Janiga, S. J., \& Costenbader, V. (2002). The transition from high school to postsecondary education for students with learning disabilities: A survey of college service coordinators. Journal of Learning Disabilities, 35(5), 463-470.

Johnson, R. B. (1997). Examining the validity structure of qualitative research Education, 118(2), 282

Keller, R. M., \& Galgay, C. E. (2010). Microaggressive experiences of people with disabilities. In Sue, D. W. (Ed.), Microaggressions and marginality: Manifestation, dynamics, and impact (pp. 241-267). Hoboken, NJ: Wiley.

Kinney, A. R., \& Eakman, A. M. (2017). Measuring self-advocacy skills among student veterans with disabilities: Implications for success in postsecondary education. Journal of Postsecondary Education and Disability, 30(4), 343-358.

Krefting, L. (1991). Rigor in qualitative research: The assessment of trustworthiness. American Journal of Occupational Therapy, 45(3), 214-222.

Kreider, C. M., Medina, S., Lan, M.-F., Wu, C.-Y., Percival, S. S., Byrd, C. E., ... \& Mann, W. C. (2018). Beyond academics: A model for simultaneously advancing campus-based supports for learning disabilities, STEM students skills for self-regulation, and mentors' knowledge for co-regulating and guiding. Frontiers in Psychology, 9, 1466. doi: 10.3389/fpsyg.2018.01466

Kurth, N., \& Mellard, D. (2006). Student perceptions of the accommodation process in postsecondary education. Journal of Postsecondary Education and Disability, 19(1), 71-84

Lee, A. (2011). A comparison of postsecondary science, technology, engineering, and mathematics (STEM) enrollment for students with and without disabilities. Career Development for Exceptional Individuals, 34(2), $72-82$.

Lee, A. (2014). Students with disabilities choosing science technology engineering and math (STEM) majors in postsecondary institutions. Journal of Postsecondary Education and Disability, 27(3), 261-272.

Lombardi, A., Gerdes, H., \& Murray, C. (2011). Validating an assessment of individual actions, postsecondary, and social supports of college students with disabilities. Journal of Student Affairs Research and Practice, 48(1), 107-126.

Love, T. S., Kreiser, N., Camargo, E., Grubbs, M. E., Kim, E. J., Burge, P. L., \& Culver, S. M. (2014). STEM faculty experiences with students with disabilities at a Land Grant institution. Journal of Education and Training Studies, 3(1), 27-38

Majocha, M., Davenport, Z., Braun, D. C., \& Gormally, C. (2018). "Everyone was nice ... but I was still left out": An interview study about deaf interns research experiences in STEM. Journal of Microbiology \& Biology Education, 19(1).

Martin, J. E., \& Marshall, L. H. (1995). ChoiceMaker: A Comprehensive Self-Determination Transition Program. Intervention in School and Clinic, 30(3), 147-156.

McCall, C., Shew, A., Simmons, D. R., Paretti, M. C., \& McNair, L. D. (2020). Exploring student disability and professional identity: Navigating sociocultural expectations in U.S. undergraduate civil engineering programs. Australasian Journal of Engineering Education, 25(1), 79-89. doi: 10.1080/22054952.2020.1720434

Moon, N. W., Todd, R. L., Morton, D. L., \& Ivey, E. (2012). Accommodating students with disabilities in science, technology, engineering, and mathematics (STEM). Atlanta: Center for Assistive Technology and Environmental Access, Georgia Institute of Technology.

Mullins, L., \& Preyde, M. (2013). The lived experience of students with an invisible disability at a Canadian university. Disability \& Society, 28(2), 147160.

National Science Foundation, National Center for Science and Engineering Statistics. (2019). Women, minorities, and persons with disabilities in science and engineering: 2019 (Special report NSF 19-304). Alexandria, VA Retrieved December 3, 2019, from www.nsf.gov/statistics/wmpd 
Newman, L., Wagner, M., Knokey, A.-M., Marder, C., Nagle, K., Shaver, D., \& Wei, X. (2011). The post-high school outcomes of young adults with disabilities up to 8 years after high school: $A$ report from the National Longitudinal Transition Study-2 (NLTS2) (NCSER 2011-3005). Washington, DC: National Center for Special Education Research.

Ofiesh, N. S. (2007). Math, science, and foreign language: Evidence-based accommodation decision making at the postsecondary level. Learning Disabilities Research \& Practice, 22(4), 237-245.

Olson, J. D., McAllister, C., Grinnell, L. D., Gehrke Walters, K., \& Appunn, F. (2016). Applying constant comparative method with multiple investigators and inter-coder reliability. Qualitative Report, 21(1), 26-42.

Pham, A. V., \& Riviere, A. (2015). Specific learning disorders and ADHD: Current issues in diagnosis across clinical and educational settings. Current Psychiatry Reports, 17(6), 38.

Pfeifer, M. A., Reiter, E. M., Hendrickson, M., \& Stanton, J. D. (2020). Speaking up: A model of self-advocacy for STEM undergraduates with ADHD and/or specific learning disabilities. International Journal of STEM Education, 7(1), 1-21.

Raue, K., \& Lewis, L. (2011). Students with disabilities at degree-granting postsecondary institutions (NCES 2011-018). Washington, DC: U.S. Government Printing Office.

Richard, M. M. (1995). Pathways to success for the college student with ADD: Accommodations and preferred practices. Journal of Postsecondary Education and Disability, 11, 16-30.

Richards, K. A. R., \& Hemphill, M. A. (2018). A practical guide to collaborative qualitative data analysis. Journal of Teaching in Physical Education, 37(2), 225-231.

Rodriguez, S. L., \& Blaney, J. M. (2020). "We're the unicorns in STEM": Understanding how academic and social experiences influence sense of belonging for Latina undergraduate students. Journal of Diversity in Higher Education. doi: 10.1037/dhe0000176

Saldaña, J. (2015). The coding manual for qualitative researchers (3 ed.). Los Angeles: Sage.

Schreffler, J., Vasquez lii, E., Chini, J., \& James, W. (2019). Universal design for learning in postsecondary STEM education for students with disabilities: A systematic literature review. International Journal of STEM Education, 6(1), 8. doi: 10.1186/s40594-019-0161-8

Sinclair, J. (2013). Why I dislike "person first" language. Autonomy, the Critical Journal of Interdisciplinary Autism Studies, 1(2)
Smith, T. E. (2001). Section 504, the ADA, and public schools: What educators need to know. Remedial and Special Education, 22(6), 335343.

Stanton, J. D., Dye, K. M., \& Johnson, M. S. (2019). Knowledge of learning makes a difference: a comparison of metacognition in introductory and senior-level biology students. CBE-Life Sciences Education, 18(2), ar24. doi: $10.1187 /$ cbe.18-12-0239

Stodden, R. A., Brown, S. E., \& Roberts, K. (2011). Disability-friendly university environments: Conducting a climate assessment. New Directions for Higher Education, 154(154), 83-92

Test, D. W., Fowler, C. H., Wood, W. M., Brewer, D. M., \& Eddy, S. (2005) A conceptual framework of self-advocacy for students with disabilities. Remedial and Special Education, 26(1), 43-54. doi: 10.1177/ 07419325050260010601

Tinto, V. (1993). Leaving college: Rethinking the causes and cures of student attrition (2nd ed.). Chicago: University of Chicago Press.

Tracy, S. J. (2010). Qualitative quality: Eight "big-tent" criteria for excellent qualitative research. Qualitative Inquiry, 16(10), 837-851. doi: 10.1177/1077800410383121

Trammell, J. (2009). Red-shirting college students with disabilities. Learning Assistance Review, 14(2), 21-31.

Tuosto, K., Johnston, J. T., Connolly, C., Lo, C., Sanganyado, E., Winter, K. A., ... \& Aamodt, C. M. (2020). Making science accessible. Science, 367(6473), 34-35. doi: 10.1126/science.aba6129

Vaccaro, A., Kimball, E. W., Wells, R. S., \& Ostiguy, B. J. (2015). Researching students with disabilities: The importance of critical perspectives. New Directions for Institutional Research, 2014(163), 25-41. doi: 10.1002/ ir.20084

Villarreal, P., III. (2002). Faculty knowledge of disability law: Implications for higher education practice. Waco, TX: Baylor University. (ERIC Document Reproduction Service No. ED 472463). Retrieved April 13, 2020, from http://eric.ed.gov/

Wehmeyer, M. L., Abery, B. H., Mithaug, D. E., \& Stancliffe, R. J. (2003). Theory in self-determination: Foundations for educational practice. Springfield, Illinois: Charles C Thomas.

Wolf, L. E. (2001). College students with ADHD and other hidden disabilities: Outcomes and interventions. Annals of the New York Academy of Sciences, 931(1), 385-395. 